\title{
Coupland's Museum of the Rapture needs contributions
}

$\mathrm{R}$ enowned author and artist, Douglas Coupland isn't delving into religion. "Rapture" is shorthand for what physically defines the notion of what is and isn't your body. "Basically, where does your body end and the universe begin?" he asks.

It's the esoteric question underlying an art exhibition planned for Toronto in the fall of 2012. Museum of the Rapture is an investigation into what can, and cannot, be considered you," explains the author of Generation X: Tales for an Accelerated Culture and 20 other books. "Whatever touches the human body, however briefly, also touches the soul."

To realize this work, he's turning to physicians and residents: "I'm asking you to join me on this unusual and, I hope, fascinating project. I think there's the possibility here, of something both sacred and awesome."

"I think the most common assumption about the body is described by the religious notion of the Rapture - one is called to heaven and one's clothing is left behind in a pile," says Coupland. "My big question is: Okay, but what else is in that pile? Clothing, sure, but what about wigs, toupées, dental veneers, pacemakers and the countless other items contained inside all of us?"

Coupland is inviting physicians and residents, to send him items that have touched the body: breast implants, dental bridges, pacemakers, stents, metal plates, dental retainers and so on. The more unusual the better.

What will the ultimate form be? "It depends on what we can accumulate," says Coupland. "If we only get three sets of false teeth and a toupée, I'll have to cancel the project, but I'm sure we can do better than that. My dream is to recreate the entire contents of what you'd find in everybody in a fully loaded 747-400, arranged seat-by-seat. So I'm aiming high."

"Rest assured it will all be used elegantly and thoughtfully — you'll be helping create something that will make you feel different about, well, what it feels like to be inside your body," adds Coupland.

The notion of the Rapture is, if nothing else, highly theatrical, and of this Coupland says, "I'll also be doing living tableaux of people who were "left behind," so to speak. These tableaux

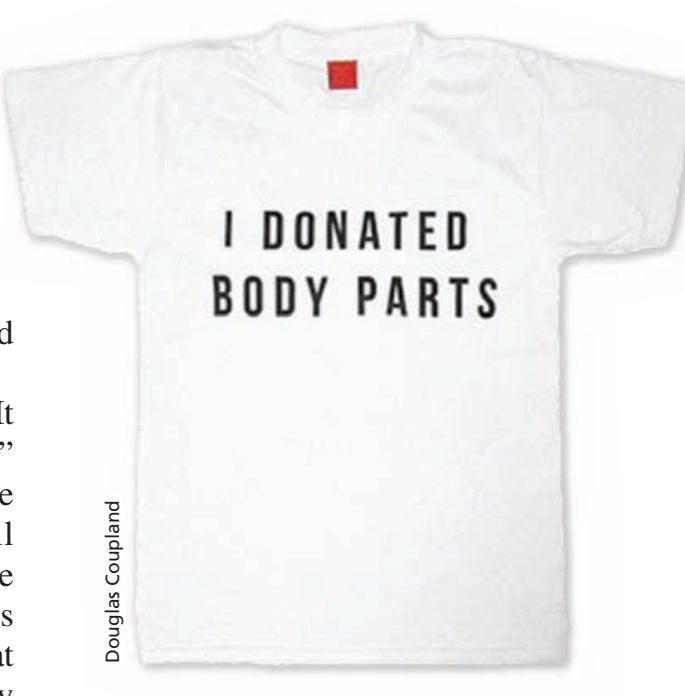

will only be for one night ... I think they'll be pretty gothic."

Coupland's visual art is a postmedium practice that employs a variety of materials and media including photography and sculpture.

For details about this project visit Coupland's blog (http://body-parts-blog .tumblr.com) or watch his video (www .coupland.com/rapture). - Barbara Sibbald, $C M A J$

CMAJ 2012. DOI:10.1503/cmaj.112046

\section{More Humanities online}

\section{Books}

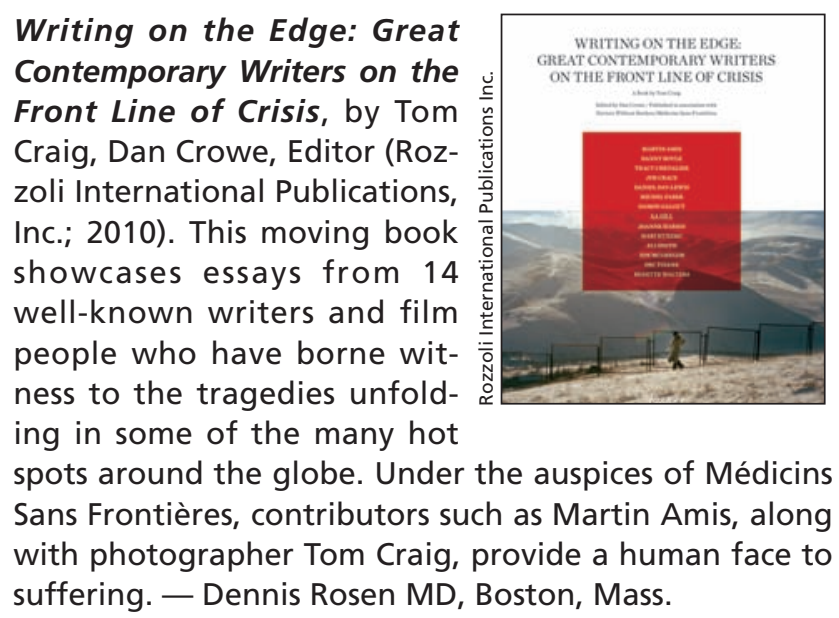

White Coat Black Hat: Adventures on the Dark Side of Medicine, by Carl Elliott (Beacon Press; 2010). This entertaining book maps out the pharmaceutical industry's dominance over the practice of medicine. But make no mistake: this is not a copycat book. Elliott, a physician and journalist, digs and finds people with surprising levels of self-awareness and the subsequent tales are told with verve. - Alan Cassels MPA, Victoria, BC

A Lifetime in Safety, by Ed Napke (Uppsala Monitoring Centre; 2011). This compilation of previously published articles by Dr. Ed Napke, founder of the Canadian Adverse Drug Reaction Reporting Program, is largely a chronicle of how the program was developed. It is a story worth reading as it brings to life Napke's passion and tremendously keen interest in helping to protect Canadians. — David U, Toronto, Ont.

CMAJ 2012. DOI:10.1503/cmaj.111794 